\title{
Wechsler Intelligence Scale for Children
}

National Cancer Institute

\section{Source}

National Cancer Institute. Wechsler Intelligence Scale for Children. NCI Thesaurus. Code C62715.

An individually administered clinical instrument for assessing the cognitive ability of children aged 6 years through 16 years 11 months. It is a psychometric test that assesses a child's current cog nitive abilities in both verbal and nonverbal areas, including verbal comprehension, perceptual reasoning, working memory, and processing speed. It was first published in 1949 and revised in 1974 (WISC-R). The third edition (WISC-III) was released in 1991 and the fourth edition (WISC-IV) in 2003. 